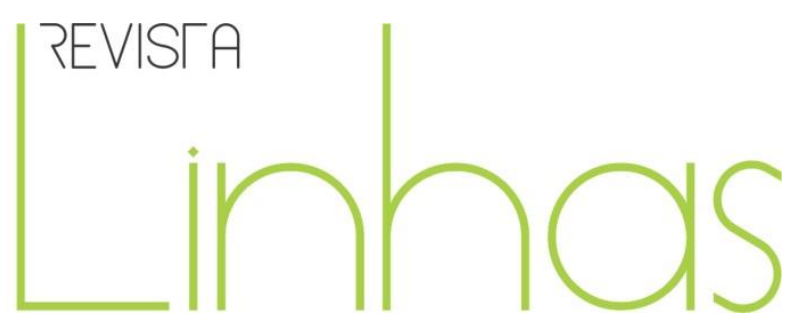

\title{
Resenha do livro "Instrumentos e Indicadores para avaliar a creche: um percurso de análise de qualidade"
}

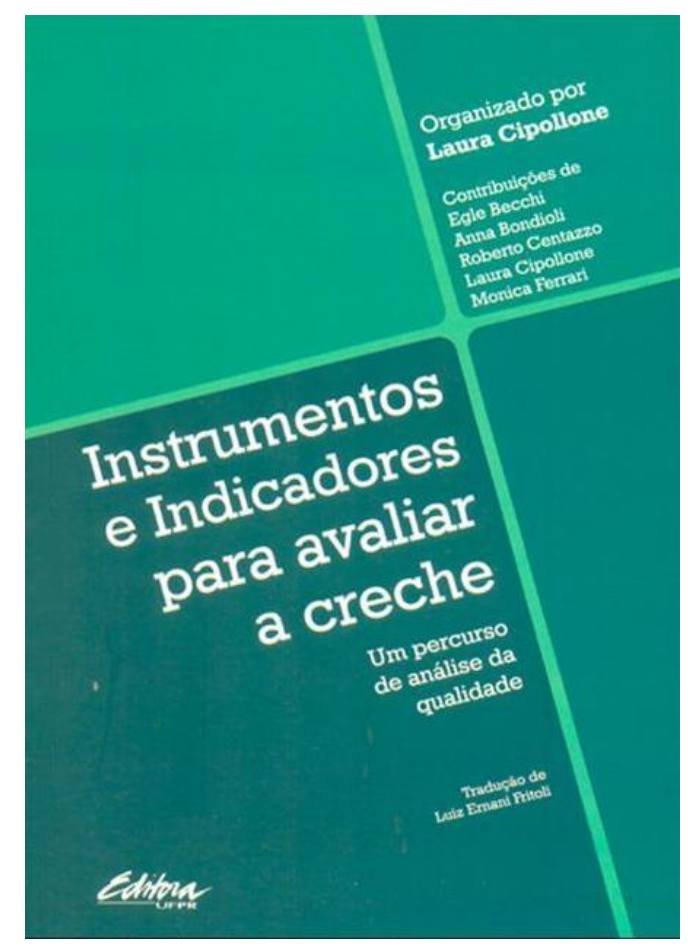

Instrumentos e Indicadores para avaliar a creche: um percurso de análise de qualidade /

Organizado por Laura Cipollone; Egle Becchi.. [et al.]; tradução de Luiz Ernani Fritoli - Curitiba: Ed. Ufpr, 2014. $231 \mathrm{p}$.

\author{
Kallyne Kafuri Alves \\ Universidade Federal do Espírito Santo - UFES - Brasil \\ kallynekafuri@hotmail.com
}

\section{Para citar esta resenha:}

ALVES, Kallyne Kafuri. Resenha do livro "Instrumentos e Indicadores para avaliar a creche: um percurso de análise de qualidade". Revista Linhas. Florianópolis, v. 19, n. 40, p. 462-468, maio/ago. 2018.

DOI: $10.5965 / 1984723819402018462$

http://dx.doi.org/10.5965/1984723819402018462 
O livro "Instrumentos e Indicadores para avaliar a creche: um percurso de análise de qualidade" reúne ensaios de reflexão metodológica a partir das experiências derivadas do curso de formação e pesquisa sobre a qualidade das creches e sua avaliação, ocorrido no período de 1992 a 1996, na região da Úmbria, localizada na Itália Central. O curso é fruto de aposta que tem como horizonte "[...] responder as exigências de indagar sobre as características da oferta formativa das Instituições da Úmbria, bem como de definir um percurso de avaliação e monitoramento da qualidade [...]" (BOCCl, p. 13).

O livro está organizado com a apresentação da edição brasileira, apresentação da edição original, introdução, duas partes, nota da redação e a apresentação dos autores. A arquitetônica atrai o leitor para o desenvolvimento do trabalho realizado e oportuniza o estudo sobre qualidade da educação em creches, configurando-se “[...] como um manual para a avaliação da qualidade da creche [...] que leva em consideração a especificidade dessa instituição não somente no que diz respeito aos aspectos educativos, mas também em relação à complexa rede de responsabilidade administrativa que a caracteriza" (CIPOLLONE, p. 15).

Na apresentação da edição brasileira, Catarina Moro e Gizele de Souza informam sobre a composição e arquitetônica da obra, detalhando aspectos sobre o trabalho desenvolvido pelo grupo italiano. Destacam que “[...] a obra em questão expressa uma fértil articulação entre a pesquisa realizada pela universidade, o gestor público e as instituições de educação infantil” (MORO; SOUZA, p. 11). Observam que a obra "[...] no tocante à avaliação, esta imbricada parceria de investigação-formação-gestão [...] e instiga a pensar como é potente o exercício contínuo e reflexivo da qualidade por meio da avaliação de contexto, subsidiados pelos princípios da crítica e da autoavaliação" (MORO; SOUZA, p. 11).

Na apresentação, Gianpiero Bocci situa o leitor sobre a conjuntura da experiência formativa que possibilita o desenvolvimento dos ensaios, pontuando que o Projeto realizado permitiu "[...] identificar e experimentar alguns instrumentos de levantamento de dados e formar coordenadores pedagógicos e profissionais do serviço para seu uso" (BOCCl, p. 14).

$\mathrm{Na}$ introdução, Laura Cipollone, além de contextualizar e sintetizar o desenvolvimento da atividade de análise e monitoramento, conceitua a perspectiva de 
avaliação, compreendendo que "[...] avaliar quer dizer, de fato, investigar sobre o estado da instituição, realizando um processo gradual de explicação da sua fisionomia" (CIPOLLONE, p. 17). Introduz elementos conceituais sobre a análise da qualidade para compreendermos o contexto metodológico do trabalho a partir das seguintes dimensões: "[...] os modelos educativos; o espaço; as atividades; as relações; as rotinas; a formação dos profissionais; a coordenação pedagógica; a relação com as famílias e com a comunidade local" (CIPOLLONE, p. 16).

Na primeira parte, intitulada "Repensar, avaliar, construir a qualidade", apresenta seis artigos, que têm como objetivo desenvolver "[...] reflexões metodológicas sobre a avaliação da qualidade nas creches e a releitura dos resultados da análise realizada" ( $p$. 26), com objetivo de informar o itinerário e a perspectiva formativa e de pesquisa, bem como os resultados alcançados com o desenvolvimento do Projeto.

No primeiro capítulo da primeira parte, intitulado "O percurso de análise da qualidade", Laura Cipollone desenvolve elementos que informam sobre as caraterísticas e as condições da qualidade, como questões relativas ao acesso à creche, a caracterização e a identidade educativa da instituição e a marca comunitária, de cuidado nas instituições (CIPOLLONE, p. 27-28). A autora informa sobre os níveis institucionais e operativos da avaliação da qualidade, desenvolvendo o conceito da qualidade tendo em vista a autonomia, o reconhecimento e as escolhas metodológicas, nas subjetividades presentes no processo.

No segundo capítulo da primeira parte, intitulado "Indicadores operativos e análise da qualidade: razões e modos de avaliar", Ana Bondioli desenvolve reflexões sobre as instituições para as crianças pequenas e a avaliação. Aborda sobre os modelos de avaliação em comparação e enfatiza a presença de três aspectos articulados à ideia de avaliar (objeto de avaliação, o ato de julgar e explicação de critérios e o objetivo de se chegar, com a avaliação, ao conhecimento acurado). Reflete sobre os objetivos e as funções da avaliação somativa e formativa, bem como os instrumentos, procedimentos e metodologia, subdivididos na avaliação com base nos padrões, objetivos, do produto e da qualidade percebida pelo usuário. Aborda os critérios e parâmetros de avaliação da creche detalhando as condições de garantias de um trabalho avaliativo e os objetivos, funções e modalidades. Defende o tema da elaboração de um sistema de indicadores, 
como [...] possível modo de conceber a avaliação e o seu significado na creche (BONDIOLI, p. 66). Entende que a avaliação da qualidade “[...] configura diversas formas de avaliação, proponíveis mediante o uso de indicadores [...] além de especificar os movimentos ainda necessários para torná-lo exequíveis" (BONDIOLI, p. 68). Aborda o monitoramento e a qualificação da instituição creche, destacando os pontos de definição de padrões estruturais, fiscalização da qualidade e promoção da qualidade (p. 69).

No terceiro capítulo da primeira parte, intitulado "Uma experiência de pesquisaformação com instrumentos avaliativos" Monica Ferrari desenvolve a ideia da avaliação da qualidade educativa do microcontexto, compreendendo que esta "[...] permite refletir sobre as próprias finalidades e desencadear um processo de pesquisa e de crescimento da realidade investigada" (FERRARI, p. 75). Aborda a experiência de pesquisa-formação: as intenções e as modalidades, apresentando sobe o uso de escalas e subescalas, as quais compreendem aspectos relativos a mobiliários e materiais à disposição das crianças, cuidados de rotina, ouvir e falar, atividades de aprendizagem, interações, organização das atividades e necessidade dos adultos. Informa dados do levantamento, apresentando três tabelas com a prova de campo e com o uso da escala de Avaliação da Creche (SVANI) em Città di Castello e Gubbio, em Terni e Amelia e, uma terceira em Úmbria. Reflete sobre questões de atividades, espaço, rotina e de observação da turma à ficha organizada pelas professoras.

No quarto capítulo da primeira parte, intitulado "Ler os dossiês", Monica Ferrari aborda os processos desenvolvidos na utilização da SVANI. Discorre sobre a construção dos dossiês, com aspectos acerca da apresentação da creche, das características organizacionais e gerenciais e da experiência de avaliação, compreendendo que "[...] as observações dos coletivos, as conclusões ou as apresentações dos dossiês mostram no seu conjunto como tais documentos constituem importante patrimônio de experiências" (FERRARI, p. 109).

No quinto capítulo da primeira parte, intitulado "Falar na creche, falar da creche", Egle Becchi aborda, em oito aspectos, o processo de leitura dos dossiês e as notas sobre qualidade, que se referem à conexão de indícios, à heterogeneidade do material, às reflexões feitas de palavras com aspectos qualitativos do trabalho, à identificação da pedagogia da primeiríssima idade, ao sentido de valores, à discussão das educadoras e 
avaliadores em relação ao instrumento, ao olhar e atenção ao adulto, ao invés da avaliação com olhar centrado na criança. Destaca reflexões sobre as ações realizadas em Úmbria (BECCHI, p. 123).

No sexto capítulo da primeira parte, intitulado "As instituições de educação infantil: no contexto organizacional do órgão local: as outras faces da qualidade" Roberto Centazzo aborda no primeiro tópico a qualidade e os serviços, compreendendo que o tema da qualidade envolve muitos significados. Reconhece a necessidade de levar em conta as mudanças no quadro de referências e defende o processo de avaliação da qualidade como subjetiva. Apresenta o modelo de qualidade percebida em figura (p. 128) e discorre sobre o entendimento do serviço público. Aborda sobre os serviços para a infância no contexto organizacional do órgão local e as muitas faces da qualidade. Apresenta o trabalho de campo e os resultados, considerando como os objetivos primários o percurso de formação-ação, a análise de qualidade percebida, tanto organizacional como gerencial. Analisa os gráficos produzidos e observa que "[...] emergem as diferenças entre os municípios maiores e os de menores dimensões", bem como “[...] escolhas de caráter organizacional” (CENTAZZO, p. 140).

Na segunda parte, intitulada "Uma bateria de instrumentos e o seu manual", desenvolvem-se seis artigos, com o objetivo de apresentar duas escalas (SVANI e ISQUEN) e um questionário complementar da SVANI, acompanhado de suas indicações de uso.

No primeiro capítulo desta segunda parte, intitulado "ISQUEN: indicadores e escala de avaliação da qualidade educativa da creche", Egle Becchi, Anna Bondioli e Monica Ferrari apresentam os indicadores e o instrumento para avaliá-los, entendendo o indicador como "[...] um índice que denota estado de fato de um dado fenômeno - e o aprecia em relação a padrões mais ou menos explícitos, e o concatena de modo sistemático internamente um modelo de tal fenômeno" (BECCHI; BONDIOLI; FERRARI, p. 149). Abordam a ideia de creche, as regras de uso ISQUEN, o índice, a folha de resposta e sugestões para o preenchimento “[...] visando a autoavaliação e a avaliação formativa” (BECCHI; BONDIOLI; FERRARI, p. 155). Composto de três partes, integra, na primeira os sujeitos, as crianças, as famílias e a equipe; na segunda, os contextos e as práticas, com os adultos e crianças, as atividades para as crianças, os móveis e materiais, os espaços e 
tempos do cotidiano e o tempo; na terceira, os saberes do fazer, com observação, planejamento, programação, avaliação e documentação; na quarta, as garantias, com a estrutura e os profissionais.

No segundo capítulo, intitulado "Questionário para a observação da qualidade de particulares momentos de rotina e de aspectos higiênicos e de segurança na creche, de atividades peculiares e de aspectos gerenciais da instituição", o grupo de trabalho de Úmbria desenvolve o uso do questionário associado à escala SVANI, com aspectos sobre as refeições, as trocas, a estrutura: normas higiênicas e de segurança, a segurança e a higiene na turma, e da creche para casa; atividades peculiares à creche e administração da creche.

No terceiro capítulo, intitulado "Questionário para a avaliação da qualidade percebida”, Roberto Centazzo aborda o propósito do instrumento, de “[...] responder a um conjunto articulado de finalidades possíveis" (CENTAZZO, p. 199). Informa os aspectos de identificar as opiniões das famílias, definir o grau de satisfação e de importância atribuído e comparar entre si várias creches no âmbito municipal. Além disso, detalha questões de infraestrutura, de destinatários, de modalidade de coleta de dados, de elaboração e de relato, apresentando o questionário para avaliação da qualidade percebida pelos usuários.

No quarto capítulo, intitulado "Questionário para a análise da qualidade organizacional”, Roberto Centazzo aborda qualidade organizacional do serviço de creche no âmbito municipal, cuja finalidade foi “[...] identificar possíveis opções diferentes, existentes" e "[...] contribuir para a elaboração de uma abordagem e de uma metodologia para análise organizacional do serviço" (CENTAZZO, p. 207). Informa questões relativas à estrutura, considerando o conceito de estrutura organizacional, o ciclo do serviço, a coordenação pedagógica e o funcionamento da creche. Apresenta as modalidades de coleta e elaboração de dados e de relato, e o questionário percebido pelos usuários.

No quinto capítulo, intitulado "Esquema de coleta de dados para a análise da qualidade gerencial”, Roberto Centazzo observa que "[...] o funcionamento de uma creche ou de um sistema de creches não tem somente implicações pedagógicas, higiênicas, organizacionais, etc.; mas tem também muitas implicações gerenciais" 
(CENTAZZO, p. 217). Reflete sobre a estrutura, modalidade de coleta e elaboração dos dados e de relatos, e apresenta o esquema e o esquema simplificado para a coleta de dados e para a análise da qualidade gerencial.

Com as notas de redação e apresentação dos autores, finaliza demonstrando a forte inspiração metodológica presente na obra, se afirmando como uma conquista nas reflexões sobre avaliação nas creches. Com isso, nos leva a conhecer e desenvolver "[...] futuras experimentações e adaptações no processo contínuo e dinâmico da análise e monitoramento da qualidade" (BOCCl, p. 14), sendo, portanto, relevante produção para a educação infantil, especialmente em tempos de afirmação de seu direito e efetivação do atendimento.

Recebido em: 07/02/2018 Aprovado em: 21/02/2018

Universidade do Estado de Santa Catarina - UDESC Programa de Pós-Graduação em Educação - PPGE 